\title{
Myocardial and vascular dysfunction in patients with rheumatoid arthritis: insights from cardiovascular magnetic resonance
}

\author{
Ntobeko A Ntusi ${ }^{1 *}$, Jane M Francis ${ }^{1}$, Paul M Matthews ${ }^{2}$, Paul B Wordsworth ${ }^{3}$, Stefan Neubauer ${ }^{1}$, \\ Theodoros Karamitsos ${ }^{1}$ \\ From 16th Annual SCMR Scientific Sessions \\ San Francisco, CA, USA. 31 January - 3 February 2013
}

\section{Background}

Rheumatoid arthritis (RA) is a multi-system, autoimmune disorder and is one of the strongest known risk factors for cardiovascular disease (CVD) morbidity and mortality. Endothelial dysfunction, accelerated atherosclerosis, vascular inflammation and myocarditis are thought to contribute to this excess CVD. Cardiovascular magnetic resonance (CMR) has the capacity of simultaneously assessing non-invasively cardiac function, altered vascular distensibility, myocardial strain and fibrosis. The purpose of this study was to assess cardiac and vascular function and to determine their relation to the presence of cardiovascular risk factors (CVRFs) and RA disease duration.

\section{Methods}

22 RA patients with no CVRFs (16 female, mean age $51 \pm$ 13), 44 RA patients with CVRFs (31 female, mean age $53 \pm$
12), 35 normal controls (31 female, mean age $49 \pm 10$ ), and 18 controls with CVRFs (10 female, mean age $51 \pm$ 11), underwent CMR at 1.5 Tesla. All patients with previously known CVD were excluded. CVRFs and duration of disease were recorded for each subject. Biventricular volumes and function, LGE, myocardial strain and vascular function were assessed by CMR. Aortic distensibility and pulse wave velocity were measured in the ascending aorta, proximal descending aorta and distal descending aorta.

\section{Results}

There were no differences in left ventricular (LV) volumes and LV ejection fraction between the 4 groups (Table 1). RA patients with CVRFs showed the greatest reduction in mid short axis circumferential systolic strain, peak diastolic strain rate, and vascular indices.

Table 1 Demographic, clinical and CMR features in RA, RA with CVRFs, controls and controls with CVRFs.

\begin{tabular}{cccccc}
\hline & Normal controls N=35 & Controls with CVRFs N=18 & RA N=22 & RA with CVRF N=44 & P Value \\
\hline Age (years) & $51.2 \pm 13.3$ & $53.4 \pm 11.8$ & $49.2 \pm 9.8$ & $51.2 \pm 10.7$ & 0.19 \\
\hline Females (\%) & $21(60.0)$ & $10(55.0)$ & $16(72.7)$ & $31(70.5)$ & 0.06 \\
\hline BMl (kg/m2) & $23.3 \pm 2.7$ & $27.3 \pm 4.2$ & $24.5 \pm 2.8$ & $28.4 \pm 7.4$ & $<0.001$ \\
\hline LVEDV $(\mathrm{ml})$ indexed to BSA & $72.3 \pm 12.2$ & $73.0 \pm 15.4$ & $74.3 \pm 19.4$ & $10.1 \pm 14.2$ & 0.72 \\
\hline LVESV $(\mathrm{ml})$ indexed to BSA & $20.7 \pm 13.2$ & $18.6 \pm 5.3$ & $21.9 \pm 9.3$ & $19.5 \pm 8.3$ & 0.65 \\
\hline LVEF & $73.8 \pm 4.5$ & $74.5 \pm 5.2$ & $3.2 \pm 0.7$ & $3.9 \pm 7.1$ & 0.17 \\
\hline LA size & $2.7 \pm 0.5$ & $3.0 \pm 0.6$ & $3.2 \pm 0.6$ & $<0.001$ \\
\hline
\end{tabular}

BME, Body mass index; LVEDV, Left ventricular end diastolic volume; BSA, Body surface area; LVESV, Left ventricular end systolic volume; LVEF, Left ventricular ejection fraction; LA, Left atrium.

${ }^{1}$ Cardiovascular Medicine, University of Oxford, Oxford, UK

Full list of author information is available at the end of the article

C Biomed Central

๑ 2013 Ntusi et al; licensee BioMed Central Ltd. This is an Open Access article distributed under the terms of the Creative Commons Attribution License (http://creativecommons.org/licenses/by/2.0), which permits unrestricted use, distribution, and reproduction in any medium, provided the original work is properly cited. 
Table 2 Systolic circumferential strain, aortic distensibility and pulse wave velocity in RA, RA with CVRFs, controls and controls with CVRFs.

\begin{tabular}{|c|c|c|c|c|c|}
\hline & $\begin{array}{l}\text { Normal controls } \\
\qquad \mathrm{N}=35\end{array}$ & $\begin{array}{l}\text { Controls with CVRFs } \\
\qquad N=18\end{array}$ & $\mathrm{RA} N=22$ & $\begin{array}{l}\text { RA with CVRFs } \\
\qquad N=44\end{array}$ & $\begin{array}{c}P \\
\text { Value }\end{array}$ \\
\hline Mid SA systolic circumferential strain & $-19.2 \pm 1.1$ & $-17.6 \pm 1.2$ & $\begin{array}{c}-17.26 \pm \\
1.4\end{array}$ & $-16.9 \pm 1.2$ & $<0.001$ \\
\hline Peak diastolic strain rate & $143.9 \pm 19.7$ & $113.6 \pm 27.9$ & $\begin{array}{l}101.9 \pm \\
23.5\end{array}$ & $103.1 \pm 20.3$ & $<0.001$ \\
\hline 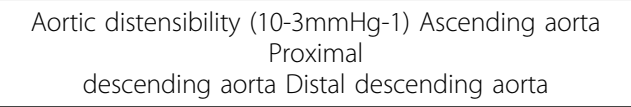 & $\begin{array}{l}3.2 \pm 1.8 \\
3.7 \pm 1.3 \\
5.7 \pm 2.0\end{array}$ & $\begin{array}{l}2.1 \pm 1.5 \\
3.1 \pm 1.4 \\
4.5 \pm 1.5\end{array}$ & $\begin{array}{l}2.2 \pm 1.5 \\
2.7 \pm 1.2 \\
4.0 \pm 1.5\end{array}$ & $\begin{array}{l}2.0 \pm 1.3 \\
2.1 \pm 1.5 \\
3.6 \pm 1.7\end{array}$ & $\begin{array}{l}0.002 \\
<0.001 \\
<0.001\end{array}$ \\
\hline $\begin{array}{c}\text { Pulse wave velocity }(\mathrm{m} / \mathrm{s}) \text { Aortic arch PWV Descending } \\
\text { aorta PWV Total PWV }\end{array}$ & $\begin{array}{l}4.2 \pm 2.6 \\
3.8 \pm 1.5 \\
4.4 \pm 1.6\end{array}$ & $\begin{array}{l}6.2 \pm 1.9 \\
6.2 \pm 1.8 \\
6.7 \pm 1.5\end{array}$ & $\begin{array}{l}6.8 \pm 3.1 \\
6.9 \pm 2.9 \\
7.7 \pm 2.9\end{array}$ & $\begin{array}{l}7.2 \pm 2.2 \\
7.7 \pm 2.3 \\
8.3 \pm 2.8\end{array}$ & $\begin{array}{l}<0.001 \\
<0.001 \\
<0.001\end{array}$ \\
\hline
\end{tabular}

SA, short axis; PWV, pulse wave velocity.

RA patients without CVRFs showed a similar degree of vascular dysfunction and deformational abnormality as controls with CVRFs (Table 2). Aortic distensibility (Rs= $-0.25, \mathrm{p}=0.048)$ and total pulse wave velocity $(\mathrm{Rs}=0.41$, $\mathrm{p}<0.001)$ correlated with RA disease duration.

\section{Conclusions}

CMR demonstrates impaired myocardial deformational characteristics and impaired vascular function in RA and in patients with CVRFs. The cardiac abnormalities due to RA appear to be independent and incremental to those due to traditional CVRFs.

\section{Funding}

$\mathrm{NN}$ is funded by the Discovery Foundation and the Nuffield Trust. SN acknowledges support from the British Heart Foundation Centre of Research Excellence, Oxford.The research was funded through an investigator-led grant from GSK.

\section{Author details}

${ }^{1}$ Cardiovascular Medicine, University of Oxford, Oxford, UK. ${ }^{2}$ GSK Clinical Imaging Centre, Imperial College, London, UK. ${ }^{3}$ Bortnar Institute and Nuffield Department of Orthopaedics, Rheumatology and Musculoskeletal Sciences, University of Oxford, Oxford, UK.

Published: 30 January 2013

doi:10.1186/1532-429X-15-S1-P221

Cite this article as: Ntusi et al:: Myocardial and vascular dysfunction in patients with rheumatoid arthritis: insights from cardiovascular magnetic resonance. Journal of Cardiovascular Magnetic Resonance 2013 15(Suppl 1):P221.
Submit your next manuscript to BioMed Central and take full advantage of:

- Convenient online submission

- Thorough peer review

- No space constraints or color figure charges

- Immediate publication on acceptance

- Inclusion in PubMed, CAS, Scopus and Google Scholar

- Research which is freely available for redistribution

Submit your manuscript at www.biomedcentral.com/submit 